\title{
Acute respiratory distress syndrome in a child with severe epileptic disorder treated successfully by extracorporeal membrane oxygenation: a case report
}

\author{
Nobuyuki Nosaka ${ }^{1,2}$, Shingo Ichiba ${ }^{1,3^{*}}$, Kohei Tsukahara ${ }^{1}$, Emily Knaup ${ }^{1}$, Kumiko Hayashi', Shingo Kasahara ${ }^{4}$, \\ Yoshinori Kobayashi ${ }^{5}$, Makio Oka ${ }^{5}$, Katsuhiro Kobayashi ${ }^{5}$, Harumi Yoshinaga ${ }^{5}$ and Yoshihito Ujike
}

\begin{abstract}
Background: Extracorporeal membrane oxygenation (ECMO) is now a candidate therapy for children with acute respiratory failure.

Case presentation: We report our experience of using central ECMO therapy for acute respiratory distress syndrome followed by seizure in a 15-month-old girl with a severe epileptic disorder. Her respiratory distress was refractory to standard medical treatment and mechanical ventilatory support. Her condition was complicated by development of a pneumothorax. The patient was successfully weaned off ECMO and discharged without deterioration of her neurological status.

Conclusion: The successful outcome in this case resulted from the central ECMO, which enabled "lung rest" and adequate cerebral blood flow. In skilled ECMO facilities, early implementation of ECMO would give some advantages to patients such as the one presented here. Given the invasiveness and the ease of the procedure, introduction of dual-lumen catheters adequately sized for pediatric patients in Japan is required.
\end{abstract}

Keywords: Acute respiratory distress syndrome (ARDS), Extracorporeal membrane oxygenation (ECMO), Severe epileptic disorder, Pediatrics

\section{Background}

Extracorporeal membrane oxygenation (ECMO) is now a candidate therapy for patients with acute respiratory failure [1-4] based on several reports of ECMO treatment for acute respiratory failure associated with influenza A H1N1 infection in both adult and pediatric patients [5-10]. Implementation of ECMO for pediatric respiratory failure has almost doubled since 2000. Approximately 350 patients have been treated annually over the past 3 years worldwide, with a $56 \%$ survival rate [11]. We report our experience of using ECMO for acute respiratory distress

\footnotetext{
* Correspondence: ecmoshingo@gmail.com

'Advanced Emergency and Critical Care Medical Center, Okayama University Hospital, Okayama, Japan

${ }^{3}$ Department of Community and Emergency Medicine, Okayama University Graduate School of Medicine, Dentistry and Pharmaceutical Sciences,

Okayama, Japan

Full list of author information is available at the end of the article
}

syndrome (ARDS) followed by seizure in a 15-month-old girl with a severe epileptic disorder. Her respiratory distress was refractory to standard medical treatment and mechanical ventilatory support and complicated by development of a pneumothorax. The patient was successfully weaned from ECMO and discharged home without deterioration in her neurological status.

\section{Case presentation}

A 15-month-old girl $(10.1 \mathrm{~kg}, 80 \mathrm{~cm})$ presented to our emergency department because of status epilepticus. She had been diagnosed as having Dravet syndrome [12] with SCN1A mutation at the age of 10 months and had received antiepileptic therapy with stiripentol, valproic acid, and clobazam. Psychomotor retardation had been detected at the age of 11 months. She had continued to 
be subject to repeated convulsions, which were managed by as-needed rectal diazepam.

She was having a partial seizure on arrival at hospital, which was aborted with intravenous midazolam. She was intubated for airway protection and transferred to our emergency intensive care unit. Sulbactam/ampicillin (300 mg/kg/day) was administered for suspected aspiration pneumonia. Once her body temperature had been controlled, she was free of seizures and did not require increased doses of antiepileptic drugs.

Her respiratory function deteriorated, however, and she developed ARDS the day after her admission. Her partial pressure of $\mathrm{O}_{2}\left(\mathrm{PaO}_{2}\right) /$ fraction of inspired $\mathrm{O}_{2}\left(\mathrm{FIO}_{2}\right)(\mathrm{P} / \mathrm{F})$ ratio was 207. She was placed on synchronized intermittent mandatory ventilation. The ventilator settings had to be gradually increased during the next 4 days from $18 / 5$ $\mathrm{cmH}_{2} \mathrm{O}$ to $20 / 10 \mathrm{cmH}_{2} \mathrm{O}$ with an increase in $\mathrm{FIO}_{2}$ from 0.40 to 0.80 . On day 6 , the ventilator settings were changed to high-frequency oscillation ventilation (HFOV) because her $\mathrm{P} / \mathrm{F}$ ratio and oxygenation index (OI) had worsened to 84 and 19, respectively. Having achieved complete muscle relaxation, the HFOV settings were adjusted (mean airway pressure $32 \mathrm{~cm} \mathrm{H}_{2} \mathrm{O}, \mathrm{FIO}_{2} 0.65$, stroke volume $60 \mathrm{~mL}$, frequency $10 \mathrm{~Hz}$ ), after which the P/F ratio and OI improved to 196 and 15.2, respectively.

Her respiratory status stabilized on HFOV. However, on day 8 her oxygenation suddenly deteriorated to a P/F ratio of 54 and OI of 55 because of development of a right pneumothorax (a complication of HFOV), which required urgent placement of a chest tube. Despite a deaeration procedure, her pulmonary function deteriorated to an OI of 78.9. A decision was made to introduce venovenous ECMO therapy. A 14 Fr return cannula was successfully inserted percutaneously into the left internal jugular vein. However, an attempt to place a $17 \mathrm{Fr}$ drainage cannula into the right internal jugular vein percutaneously failed because of an error in guidewire handling and formation of a hematoma on her neck.

In this emergency situation, the therapeutic strategy was aggressively changed to venoarterial ECMO. With the help of a cardiac surgeon, a $21 \mathrm{Fr}$ drainage cannula and $12 \mathrm{Fr}$ return cannula were placed in the right atrium and ascending aorta, respectively, via mid-sternotomy. The ECMO flow was initially set at $1 \mathrm{~L} / \mathrm{min}$ with rotational frequency of the centrifugal pump. After introduction of $70 \% \mathrm{O}_{2}$ via ECMO, her arterial blood gas values dramatically improved $\left(\mathrm{PaO}_{2} 404 \mathrm{mmHg}\right)$, and the $\mathrm{FIO}_{2}$ from mechanical ventilation was reduced to $30 \%$ with a lower tidal volume and lower airway pressure (positive end-expiratory pressure $8 \mathrm{cmH}_{2} \mathrm{O}$, inspiration time 1.51.8 seconds, frequency $5 / \mathrm{min}$ ). Because of continuous oozing from the thoracotomy site and hematoma formation in the right thoracic cavity, substantial volumes of blood were transfused during ECMO management (red blood cell concentrate $3250 \mathrm{~mL}$; fresh frozen plasma 920 $\mathrm{mL}$; platelets $1350 \mathrm{~mL}$ ). As the patient was already fluidoverloaded because of her severe hypoxic and inflammatory status prior to introducing ECMO, continuous renal replacement therapy was introduced after stabilization on ECMO to control her fluid balance precisely. To reduce the risk of bleeding, nafamostat mesilate was used as an anticoagulant, with a targeted activated clotting time of 150-160 s. The ECMO circuit used had a heparin coating.

On day 12 (fourth day of ECMO), mediastinal lavage and removal of hematoma from the right thoracic cavity was performed through re-thoracotomy with no complications. On day 13 (fifth day of ECMO), $600 \mathrm{mg}$ of surfactant was administered mainly into the right upper and middle lobar branches, with direct bronchoscopic observation. According to her lung compliance measured by the ventilator (Evita Infinity V500, Dräger, Lübeck, Germany) and serial chest X-ray films, there was gradual improvement, especially after the surfactant therapy (Figure 1). During ECMO support, central venous oxygen saturation was stable at around $70 \%$.

Stable hemodynamics having been achieved after 7 days of ECMO support, the patient was successfully weaned from ECMO on day 15. Continuous renal replacement therapy was discontinued simultaneously. Tracheal extubation was performed on day 26. She was discharged from our intensive care unit on day 34 and discharged home on day 79 without deterioration in her neurological status.

Support from multiple departments facilitated rapid introduction of central ECMO and stabilization of the patient, which contributed greatly to successful treatment of this pediatric patient with ARDS [2]. There may be counterarguments against using central respiratory ECMO, but it enabled provision of complete "lung rest," attenuating ventilator-induced lung injury $[13,14]$, as did aggressive treatment with the surfactant. Because of the patient's abnormal vessel course and small vessel size, which are associated with Dravet syndrome, there was no adequately sized double-lumen cannula for this patient that was available in Japan. The use of bilateral jugular vein cannulation in ECMO has some risk of increasing the intracranial venous pressure and development of superior vena cava syndrome. Also, if we had chosen to cannulate the jugular veins bilaterally in this patient, it may have caused deterioration in her neurodevelopmental status. Therefore, we believe that central ECMO was a reasonable choice for this patient.

We decided to implement ECMO after detecting a pneumothorax, which is one of the complications of HFOV. Whether the timing of ECMO introduction was optimal in this patient is open to debate. Our respiratory management strategy for pediatric ARDS patients is based on the OI as follows: With OI $\geq 20$, implement HFOV; with OI $\geq 30$, implement ECMO. Two large randomized 


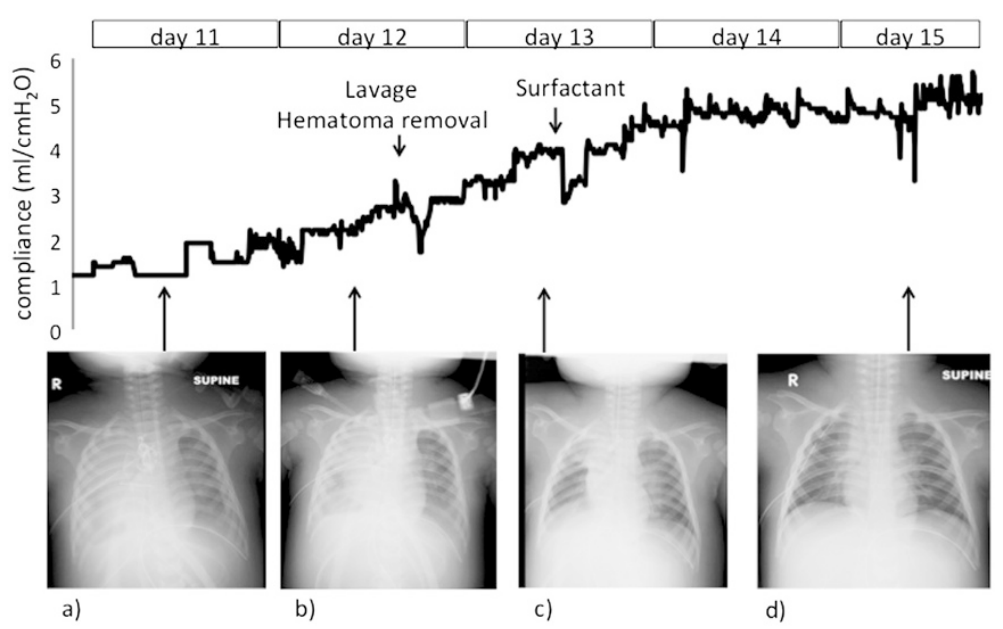

Figure 1 Lung compliance and chest radiographs. The line graph shows improvement in lung compliance as calculated by the mechanical ventilator. Lung compliance was temporarily compromised with interventions such as lavage or surfactant administration; however, it subsequently recovered to adequate levels. Parallel with recovery of lung compliance, the radiolucency of the lung gradually improved. a) Day 11. b) Day 12 before lavage and hematoma removal. c) Day 13 before surfactant administration. d) Day 15.

controlled trials comparing HFOV with conventional lungprotective ventilation were published in 2013: the Oscillation for Acute Respiratory Distress Syndrome Treated Early (OSCILLATE) trial [15] and the Oscillation in ARDS (OSCAR) trial [16]. These trials suggested that, in adults with early moderate-to-severe ARDS, HFOV conferred no benefit and may have been harmful [17]. Historically, HFOV is preferred for lung protective therapy in small children. However the pathophysiology of acute respiratory failure in neonates is known to differ from that of older infants and children. Thus, HFOV may also be harmful to children. With sufficient understanding of the characteristics of both HFOV and ECMO, lowering the criteria for implementation of ECMO might improve patients' safety and outcomes.

Easier, less invasive implementation of ECMO should provide great advantages for pediatric patients with severe ARDS. The current technique in Japan involves implementing venovenous ECMO using bilateral jugular veins or venoarterial ECMO using an internal jugular vein and a common carotid artery. The internal diameter of the catheter is crucial to facilitating sufficient drainage of venous blood [18]. However, the available catheters with sufficiently large diameters (larger than $15 \mathrm{Fr}$ ) in Japan may be too long for pediatric patients. This makes aspects of the cannulation procedure (e.g., handling of the guidewire) more difficult, as we experienced in this patient. Recently, dual-lumen catheters have gained popularity in western countries for administering pediatric ECMO [19]. Currently, these devices are unavailable in Japan. However, given the invasiveness and the ease of the procedure, introduction of dual-lumen catheters for pediatric patients is urgently required in our country.
ECMO enabled safe administration of surfactant into targeted lung lobar branches with bronchoscopic guidance. ECMO provides a safe setting for procedures that are risky during ventilation. Several researchers have reported that surfactant is effective in patients with ARDS, especially children $[20,21]$. Based on our observations of improvement in lung compliance, we believe that surfactant contributed to our patient's recovery. However, further research to verify the effect of surfactant in ARDS patients is needed. It would be desirable to accumulate a series of pediatric ARDS patients who have been treated with surfactant and in whom relevant variables, including lung compliance, have been measured.

Severe neurological disorders have been thought to contraindicate the use of ECMO [22]. According to the most recent Extracorporeal Life Support Organization guidelines, however, most contraindications are relative. Hence, the risk of a procedure should be balanced against its potential benefits [18]. Pneumonia is one of the most frequent causes of death in epileptic patients, including those with Dravet syndrome [23-25]. The development of ECMO has increased the range of means of managing such patients. However, ECMO remains an expensive treatment with a high risk of complications. The indications should be carefully scrutinized, case by case. From this perspective, the possibility of implementing ECMO should be considered at an early stage to ensure sufficient time to discuss its applicability.

\section{Conclusions}

We implemented central venoarterial ECMO for respiratory failure in a pediatric patient with a severe epileptic disorder in an emergency situation. Central respiratory 
ECMO could be a reasonable choice for small pediatric patients with severe ARDS. With enough understanding of the characteristics of ECMO, its early implementation might improve outcomes. Our results suggest that the introduction of dual-lumen catheters for pediatric patients to Japan could lead to safer, less invasive implementation of ECMO.

\section{Consent}

Written informed consent was obtained from the parents of this patient for publication of these data and any accompanying images. A copy of the written consent is available for review by the Editor of this Journal.

\section{Abbreviations}

ARDS: Acute respiratory distress syndrome; ECMO: Extracorporeal membrane oxygenation; $\mathrm{FlO}_{2}$ : Fraction of inspired $\mathrm{O}_{2} ; \mathrm{HFOV}$ : High-frequency oscillation ventilation; Ol: Oxygenation index; $\mathrm{PaO}_{2}$ : Partial pressure of oxygen; P/F: Pressure of $\mathrm{O}_{2} /$ fraction of inspired $\mathrm{O}_{2}$.

\section{Competing interests}

The authors declare that they have no competing interests.

\section{Authors' contributions}

NN drafted the manuscript. NN, SI, EK, KT, KH, SK, YK, MO, KK, and HY contributed to treating the patient. SI and $Y U$ revised and edited the manuscript. All authors have read and approved the final manuscript.

\section{Acknowledgment}

The authors thank Edanz (http://www.edanzediting.co.jp) for the English language review.

\section{Author details \\ ${ }^{1}$ Advanced Emergency and Critical Care Medical Center, Okayama University Hospital, Okayama, Japan. ²Department of Pediatrics, Okayama University Graduate School of Medicine, Dentistry and Pharmaceutical Sciences, Okayama, Japan. ${ }^{3}$ Department of Community and Emergency Medicine, Okayama University Graduate School of Medicine, Dentistry and Pharmaceutical Sciences, Okayama, Japan. ${ }^{4}$ Department of Cardiovascular Surgery, Okayama University Graduate School of Medicine, Dentistry and Pharmaceutical Sciences, Okayama, Japan. ${ }^{5}$ Department of Child Neurology, Okayama University Graduate School of Medicine, Dentistry and Pharmaceutical Sciences, Okayama, Japan.}

Received: 30 June 2014 Accepted: 13 March 2015

Published online: 01 April 2015

\section{References}

1. Peek GJ, Sosnowski AW. Extra-corporeal membrane oxygenation for paediatric respiratory failure. Br Med Bull. 1997;53:745-56.

2. Peris A, Cianchi G, Biondi S, Bonizzoli M, Pasquini A, Bonacchi M, et al. Extracorporeal life support for management of refractory cardiac or respiratory failure: initial experience in a tertiary centre. Scand J Trauma Resusc Emerg Med. 2010;21:18-28.

3. Maslach-Hubbard A, Bratton SL. Extracorporeal membrane oxygenation for pediatric respiratory failure: History, development and current status. World J Crit Care Med. 2013;4:29-39.

4. Extracorporeal Life Support Organization (ELSO): Guidelines for Pediatric Respiratory Failure. Ver. 1.3, November 2013. [https://www.elso.org/Portals/0/ IGD/Archive/FileManager/929122ae88cusersshyerdocumentselsoguidelines generalalleclsversion1.3.pdf]

5. Buckley E, Sidebotham D, McGeorge A, Roberts S, Allen SJ, Beca J. Extracorporeal membrane oxygenation for cardiorespiratory failure in four patients with pandemic H1N1 2009 influenza virus and secondary bacterial infection. Br J Anaesth. 2010;104:326-9.
6. Noah MA, Peek GJ, Finney SJ, Griffiths MJ, Harrison DA, Grieve R, et al. Referral to an extracorporeal membrane oxygenation center and mortality among patients with severe 2009 influenza A(H1N1). JAMA. 2011;306:1659-68.

7. Australia and New Zealand Extracorporeal Membrane Oxygenation (ANZ ECMO) Influenza Investigators, Davies A, Jones D, Bailey M, Beca J, Bellomo R, et al. Extracorporeal Membrane Oxygenation for 2009 Influenza A(H1N1) Acute Respiratory Distress Syndrome. JAMA. 2009;302:1888-95.

8. Turner DA, Rehder KJ, Peterson-Carmichael SL, Ozment CP, Al-Hegelan MS, Williford WL, et al. Extracorporeal membrane oxygenation for severe refractory respiratory failure secondary to 2009 H1N1 influenza A. Respir Care. 2011;56:941-6.

9. Freed DH, Henzler D, White CW, Fowler R, Zarychanski R, Hutchison J, et al. Extracorporeal lung support for patients who had severe respiratory failure secondary to influenza A (H1N1) 2009 infection in Canada. Can J Anaesth. 2010;57:240-7.

10. Tokuhira N, Shime N, Inoue M, Kawasaki T, Sakurai Y, Kurosaka N, et al. Mechanically ventilated children with 2009 pandemic influenza A/H1N1: results from the National Pediatric Intensive Care Registry in Japan. Pediatr Crit Care Med. 2012;13:e294-8.

11. Paden ML, Conrad SA, Rycus PT, Thiagarajan RR, ELSO Registry. Extracorporeal Life Support Organization Registry Report 2012. ASAIO J. 2013;59:202-10.

12. Akiyama M, Kobayashi K, Ohtsuka Y. Dravet syndrome: a genetic epileptic disorder. Acta Med Okayama. 2012;66:369-76.

13. Fan E, Villar J, Slutsky AS. Novel approaches to minimize ventilator-induced lung injury. BMC Med. 2013;28:85.

14. The Acute Respiratory Distress Syndrome Network. Ventilation with lower tida volumes as compared with traditional tidal volumes for acute lung injury and the acute respiratory distress syndrome. N Engl J Med. 2000;342:1301-8.

15. Ferguson ND, Cook DJ, Guyatt GH, Mehta S, Hand L, Austin P, et al. High-frequency oscillation in early acute respiratory distress syndrome. N Engl J Med. 2013;368:795-805.

16. Young D, Lamb SE, Shah S, MacKenzie I, Tunnicliffe W, Lall R, et al. High-frequency oscillation for acute respiratory distress syndrome. N Engl J Med. 2013;368:806-13.

17. Goffi A, Ferguson ND. High-frequency oscillatory ventilation for early acute respiratory distress syndrome in adults. Curr Opin Crit Care. 2014;20:77-85.

18. Extracorporeal Life Support Organization (ELSO) General Guidelines for all ECLS Cases. [https://www.elso.org/Portals/0/IGD/Archive/FileManager/929122ae88c usersshyerdocumentselsoguidelinesgeneralalleclsversion1.3.pdf]

19. Fallon SC, Shekerdemian LS, Olutoye OO, Cass DL, Zamora IJ, Nguyen T, et al. Initial experience with single-vessel cannulation for venovenous extracorporeal membrane oxygenation in pediatric respiratory failure. Pediatr Crit Care Med. 2013;14:366-73.

20. Kula R, Maca J, Sklienka P, Tichy J, Szturz P, Jahoda J, et al. Exogenous surfactant as a component of complex non-ECMO therapy of ARDS caused by influenza A virus (2009 H1N1). Bratisl Lek Listy. 2011;112:218-22.

21. Willson DF, Notter RH. The future of exogenous surfactant therapy. Respir Care. 2011;56:1369-86

22. Extracorporeal Life Support Organization (ELSO) Guidelines for Pediatric Respiratory Failure. Ver. 1.1, April 2009. [http://www.elso.med.umich.edu/ wordforms/elso\%20pt\%20specific\%20guidelines.pdf]

23. Terra VC, Scorza FA, Arida RM, Fernandes RM, Wichert-Ana L, Machado HR, et al. Mortality in children with severe epilepsy: 10 years of follow-up. Arq Neuropsiquiatr. 2011;69:766-9.

24. Lhatoo SD, Sander JW. Cause-specific mortality in epilepsy. Epilepsia. 2005;46 Suppl 11:36-9.

25. Forsgren L, Hauser WA, Olafsson E, Sander JW, Sillanpää M, Tomson T. Mortality of epilepsy in developed countries: a review. Epilepsia. 2005;46(11):18-27. 